\title{
Barnesiella viscericola gen. nov., sp. nov., a novel member of the family Porphyromonadaceae isolated from chicken caecum
}

\author{
Correspondence \\ Mitsuo Sakamoto \\ sakamoto@jcm.riken.jp
}

\author{
Mitsuo Sakamoto, ${ }^{1}$ Pham Thi Ngoc Lan ${ }^{1,2}$ and Yoshimi Benno ${ }^{1}$ \\ ${ }^{1}$ Microbe Division, Japan Collection of Microorganisms, RIKEN BioResource Center, Wako, \\ Saitama 351-0198, Japan \\ ${ }^{2}$ Institute of Biotechnology, Vietnamese Academy of Science and Technology, Hanoi, Vietnam
}

\begin{abstract}
Two bacterial strains isolated from chicken caecum, $C 46^{\top}$ and $\mathrm{C} 47$, were characterized using a polyphasic taxonomic approach that included analysis of the phenotypic and biochemical features, cellular fatty acid profiles, menaquinone profiles and phylogenetic position (using 16S rRNA gene sequence analysis). The $16 \mathrm{~S}$ rRNA gene sequence analysis showed that these strains belonged to the family Porphyromonadaceae. These strains shared 100\% 16S rRNA gene sequence similarity with each other and were related to Parabacteroides distasonis (showing $86 \%$ sequence similarity). The strains were found to be obligately anaerobic, non-pigmented, non-spore-forming, non-motile, Gram-negative rods. Growth of the strains was inhibited on medium containing $20 \%$ bile. The major menaquinones of the isolates were MK-11 and MK-12. This menaquinone composition was different from those of other genera of the family Porphyromonadaceae, such as Parabacteroides (in which the predominant menaquinones are MK-9 and MK-10), Porphyromonas (MK-9 and MK-10) and Tannerella (MK-10 and MK-11). This is an important chemotaxonomic characteristic of these micro-organisms. The DNA G $+\mathrm{C}$ content of strain $\mathrm{C} 46^{\top}$ is 52.0 mol\%. On the basis of these data, strains $C 46^{\top}$ and $\mathrm{C} 47$ represent a novel genus and species, for which the name Barnesiella viscericola gen. nov., sp. nov. is proposed. The type strain of Barnesiella viscericola is $\mathrm{C}^{4} 6^{\top}\left(=\mathrm{JCM} 13660^{\top}=\mathrm{DSM} 18177^{\top}\right)$.
\end{abstract}

Previous phylogenetic analyses of chicken caecal microbiota, based on 16S rRNA gene clone library analyses, have revealed a large number of novel phylotypes (Lan et al., 2002; Zhu et al., 2002). Using a special anaerobic culture technique, referred to as the 'plate-in-bottle' method (Mitsuoka et al., 1969), attempts were made to cultivate bacteria from chicken caecum. We found that many of the isolates obtained were members of the order 'Bacteroidales'. From these isolates, we recently proposed three novel Bacteroides species: Bacteroides barnesiae, Bacteroides gallinarum and Bacteroides salanitronis (Lan et al., 2006). Analyses of the 16S rRNA gene sequences of two other isolates, which could not grow on medium containing $20 \%$ bile, showed that these strains represented a new subline within the family Porphyromonadaceae. These strains shared $100 \% 16 S$ rRNA gene sequence similarity with each other and were related to Parabacteroides distasonis (86\% sequence similarity). In the present study, we have attempted to determine the taxonomic status of these strains.

The GenBank/EMBL/DDBJ accession number for the $16 \mathrm{~S}$ rRNA gene sequence of strain $C 46^{\top}$ is $A B 267809$.
Strains $\mathrm{C} 46^{\mathrm{T}}$ and $\mathrm{C} 47$ used in the present study were isolated from chicken caecum (Lan et al., 2002) and were maintained on Eggerth Gagnon (EG) agar (Merck) supplemented with $5 \%(\mathrm{v} / \mathrm{v})$ horse blood for 2 days at $37^{\circ} \mathrm{C}$ in an atmosphere comprising $100 \% \mathrm{CO}_{2}$. The ability to tolerate bile was tested using Bacteroides bile aesculin agar (Shah, 1992). Physiological reactions were determined with an API 20A anaerobe test kit, in duplicate, as recommended by the manufacturer (bioMérieux). The metabolic end products were prepared as described previously (Holdeman et al., 1977) and were analysed as described by Sakamoto et al. (2005). Fatty acid methyl esters were obtained from about $40 \mathrm{mg}$ wet cells by saponification, methylation and extraction using the method of Miller (1982) but with minor modifications as described by Kuykendall et al. (1988). Cellular fatty acid profiles were determined using the MIDI microbial identification system (Microbial ID). Isoprenoid quinones were extracted (Komagata \& Suzuki, 1987) and analysed (Sakamoto et al., 2002) as described previously. Biochemical reactions were determined with the Rapid ID 32A anaerobe identification kit, in duplicate, as recommended by the manufacturer (bioMérieux). Chromosomal DNA was isolated by means of previously described methods (Marmur, 1961; Saito \& Miura, 1963), with 
some modifications. The DNA G $+\mathrm{C}$ content was determined by using the HPLC method of Tamaoka \& Komagata (1984). The elution solvent was a mixture of $0.02 \mathrm{M}$ $\mathrm{NH}_{4} \mathrm{H}_{2} \mathrm{PO}_{4}$ and acetonitrile $(20: 1, \mathrm{v} / \mathrm{v})$. The $16 \mathrm{~S}$ rRNA gene sequence was analysed as described previously (Sakamoto et al., 2002). Related sequences were aligned with the CLUSTAL W program (Thompson et al., 1994) and corrected by manual inspection. Nucleotide substitution rates $\left(K_{\text {nuc }}\right.$ values) were calculated (Kimura, 1980) after gaps and unknown bases had been eliminated. The phylogenetic tree was constructed by using the neighbour-joining method (Saitou \& Nei, 1987). Bootstrap resampling analysis (Felsenstein, 1985) was performed to estimate the confidence of the tree topologies.

Strains $\mathrm{C} 46^{\mathrm{T}}$ and $\mathrm{C} 47$ were obligately anaerobic, non-sporeforming, non-motile, Gram-negative rods. The growth of these isolates was inhibited on a medium containing $20 \%$ bile. Cells on EG agar were $0.8-1.6 \times 1.7-11 \mu \mathrm{m}$ in size and occurred singly. Colonies on EG agar plates were $1-2 \mathrm{~mm}$ in diameter, grey to off-white-grey, circular, entire, slightly convex and smooth. The physiological and biochemical characteristics are given in the species description.

The major cellular fatty acids of the two novel strains were anteiso- $\mathrm{C}_{15: 0}$ and iso- $\mathrm{C}_{15: 0}(41-42 \%$ and $16-18 \%$, respectively; Table 1). The amount of anteiso- $\mathrm{C}_{15: 0}$ was relatively high in comparison with amounts reported for members of the genera Bacteroides (27-42\%), Parabacteroides

Table 1. Cellular fatty acid compositions of strains $\mathrm{C} 46^{\top}$ and $\mathrm{C} 47$

Summed feature 3 contained an unknown fatty acid (equivalent chain length 13.570) and/or iso- $\mathrm{C}_{15: 0}$ ALDE. Values shown are percentages of total fatty acids.

\begin{tabular}{|c|c|c|}
\hline Fatty acid & $\mathrm{C} 46^{\mathrm{T}}$ & $\mathrm{C} 47$ \\
\hline \multicolumn{3}{|l|}{ Saturated straight-chain } \\
\hline $\mathrm{C}_{14: 0}$ & 1.3 & 1.0 \\
\hline $\mathrm{C}_{16: 0}$ & 4.8 & 4.6 \\
\hline $\mathrm{C}_{18: 0}$ & 1.0 & 1.0 \\
\hline \multicolumn{3}{|c|}{ Unsaturated straight-chain } \\
\hline $\mathrm{C}_{18: 1} \omega 9 c$ & 1.4 & 1.3 \\
\hline $\mathrm{C}_{18: 2} \omega 6,9 c$ & 1.5 & 1.4 \\
\hline \multicolumn{3}{|l|}{ Hydroxy } \\
\hline iso- $\mathrm{C}_{15: 0} 3-\mathrm{OH}$ & 4.4 & 4.7 \\
\hline $\mathrm{C}_{16: 0} 3-\mathrm{OH}$ & 2.4 & 2.3 \\
\hline iso- $\mathrm{C}_{17: 0} 3-\mathrm{OH}$ & 6.1 & 6.0 \\
\hline anteiso- $\mathrm{C}_{17: 0} 3-\mathrm{OH}$ & 1.9 & 1.8 \\
\hline \multicolumn{3}{|c|}{ Saturated branched-chain } \\
\hline iso- $\mathrm{C}_{15: 0}$ & 16.4 & 17.7 \\
\hline anteiso- $\mathrm{C}_{15: 0}$ & 41.6 & 41.3 \\
\hline iso- $\mathrm{C}_{17: 0}$ & 3.9 & 4.0 \\
\hline anteiso- $\mathrm{C}_{17: 0}$ & 4.8 & 4.9 \\
\hline Summed feature 3 & 2.8 & 3.1 \\
\hline
\end{tabular}

(25-32\%) and Prevotella (7-37\%) (Sakamoto \& Benno, 2006; Sakamoto et al., 2002, 2005). Although Proteiniphilum acetatigenes also possessed a large proportion of anteiso$\mathrm{C}_{15: 0}(46.21 \%)$, the proportion of iso- $\mathrm{C}_{15: 0}$ was low (3.77\%) (Chen \& Dong, 2005).

The major menaquinones of strains $\mathrm{C} 46^{\mathrm{T}}$ and $\mathrm{C} 47$ were MK-11 (65-66\%) and MK-12 (21-24\%). MK-10 was also present (10-11\%). This menaquinone composition differed from those of members of the genera Parabacteroides (in which the predominant menaquinones are MK-9 and MK10), Porphyromonas (MK-9 and MK-10) and Tannerella (MK-10 and MK-11) (Sakamoto \& Benno, 2006; Sakamoto et al., 2002). Among the strains isolated from chicken caecum, B. salanitronis $\mathrm{BL} 78^{\mathrm{T}}$ also exhibited MK-11 (43\%) and MK-12 (43\%) as the main components (Lan et al., 2006).

The DNA G $+\mathrm{C}$ contents of strains $\mathrm{C} 46^{\mathrm{T}}$ and $\mathrm{C} 47$ were in the range $52.0-52.2 \mathrm{~mol} \%$. These values are somewhat higher than those for the members of other genera in the family Porphyromonadaceae (Table 2).

Approximately 1500 bases of the 16S rRNA gene sequence were determined for the novel isolates. Strains $\mathrm{C}_{4} 6^{\mathrm{T}}$ and $\mathrm{C} 47$ shared $100 \%$ sequence similarity with each other and were most closely related ( $96 \%$ sequence similarity) to uncultured bacterial clones isolated in the course of a human caecum mucosal biopsy (Eckburg et al., 2005). In addition, the novel strains were related to Parabacteroides distasonis ( $86 \%$ sequence similarity). For the phylogenetic analysis, 1340 bp (positions 61-1375; Escherichia coli numbering system) sequences of each species were used. 16S rRNA gene sequence analyses of the two novel strains showed that the strains represented a novel subline within the family Porphyromonadaceae (Fig. 1). Distantly related taxa included members of the genera Dysgonomonas (84.0-85.9\% sequence similarity), Paludibacter (84.4\% sequence similarity), Parabacteroides ( $84.4-86.0 \%$ sequence similarity), Porphyromonas (81.4-84.2\% sequence similarity), Proteiniphilum $(83.8 \%$ sequence similarity) and Tannerella (84.1-85.1\% sequence similarity).

Although strains $\mathrm{C} 6^{\mathrm{T}}$ and $\mathrm{C} 47$ were included in the family Porphyromonadaceae, their menaquinone composition (MK-11 and MK-12) differed from those of members of other genera of the family Porphyromonadaceae, i.e. Paludibacter (MK-8), Parabacteroides (MK-9 and MK-10), Porphyromonas (MK-9 and MK-10) and Tannerella (MK-10 and MK-11). The menaquinone composition, therefore, is an important chemotaxonomic characteristic of the isolates. In addition, the high $\mathrm{G}+\mathrm{C}$ content of the DNA of the two strains is also useful for differentiating them from members of known genera. These results suggest that a novel genus should be established to accommodate strains $\mathrm{C} 46^{\mathrm{T}}$ and C47.

On the basis of the above-mentioned findings and the results of the 16S rRNA gene sequence analysis, strains $\mathrm{C} 46^{\mathrm{T}}$ and 
Table 2. Differential characteristics of strains $C 46^{\top}$ and $C 47$ and some related taxa

Taxa: 1, strains C46 ${ }^{\mathrm{T}}$ and C47 (Barnesiella gen. nov.); 2, Dysgonomonas; 3, Paludibacter; 4, Parabacteroides; 5, Porphyromonas; 6, Proteiniphilum; 7, Tannerella. Data were taken from Chen \& Dong (2005), Hofstad et al. (2000), Lawson et al. (2002), Sakamoto \& Benno (2006), Sakamoto et al. (2002), Ueki et al. (2006) and this study. Abbreviations: NF, non-fermentative; F, fermentative; A, acetic acid; B, butyric acid; IV, isovaleric acid; L, lactic acid; P, propionic acid; PA, phenylacetic acid; S, succinic acid; NT, not tested; V, variable; UASB, upflow anaerobic sludge blanket.

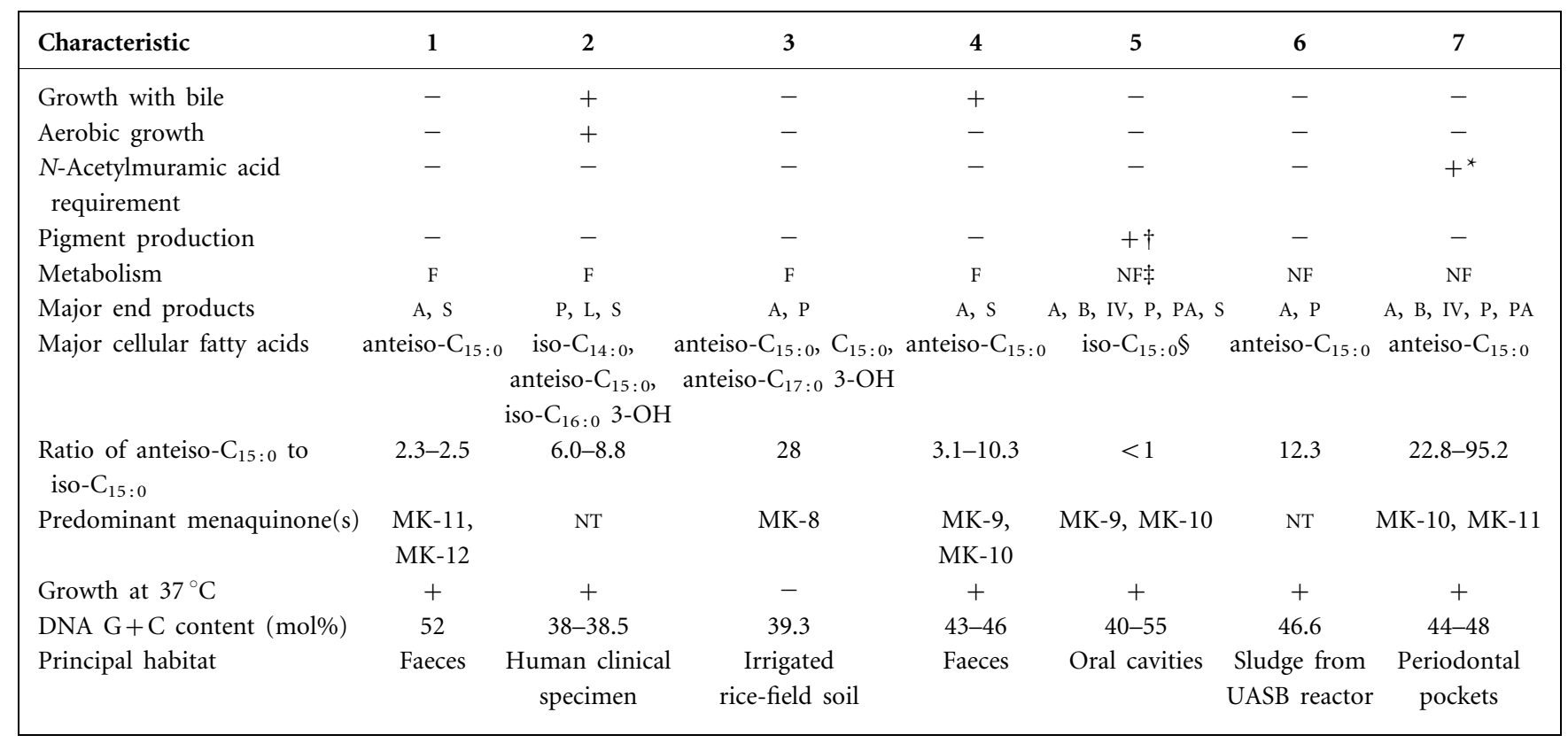

${ }^{\star}$ Bite-wound isolates do not require $N$-acetylmuramic acid for growth.

$\dagger$ Porphyromonas catoniae does not produce a black pigment on blood agar.

$¥$ Some species are weakly saccharolytic.

$\$$ Porphyromonas catoniae contains approximately equal amounts of iso- and anteiso- $\mathrm{C}_{15: 0}$ as the predominant fatty acids.

C47 represent a novel genus and species, for which the name Barnesiella viscericola gen. nov., sp. nov. is proposed. Differential characteristics of Barnesiella gen. nov. and some related taxa are shown in Table 2.

\section{Description of Barnesiella gen. nov.}

Barnesiella (Bar.ne.si.el'la. N.L. dim. fem. n. Barnesiella named after the British microbiologist Ella M. Barnes, who

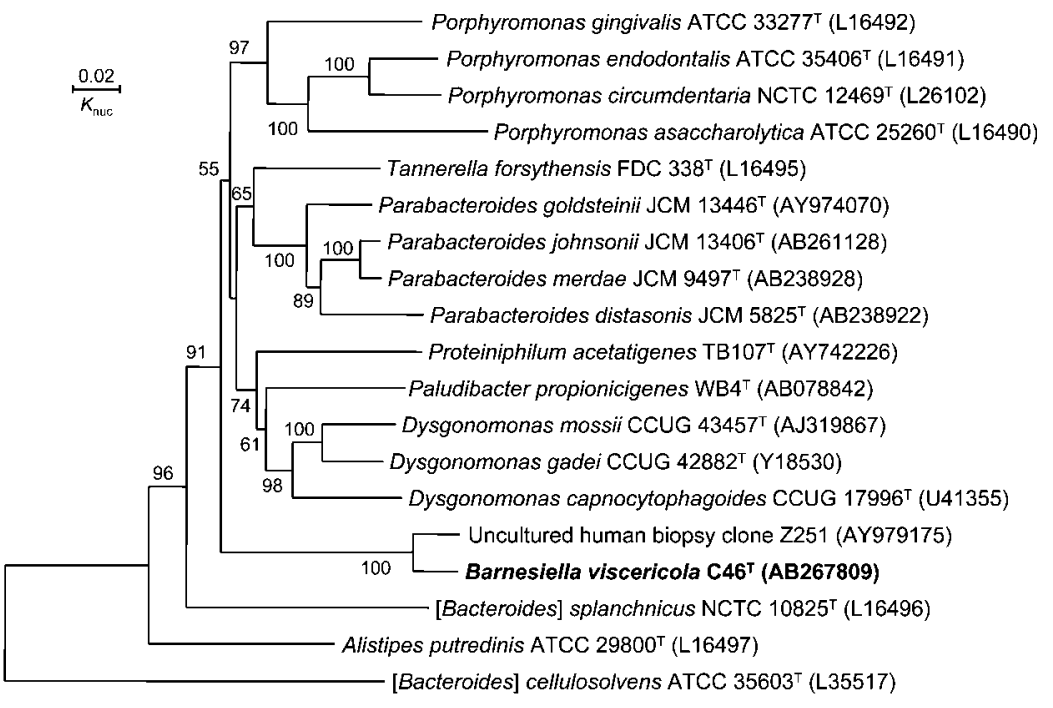

Fig. 1. Neighbour-joining phylogenetic tree, based on 16S rRNA gene sequences, showing the relationship between strain $\mathrm{C} 46^{\top}$ and some related taxa. Accession numbers for the $16 \mathrm{~S}$ rRNA gene sequences are given for each strain. Numbers at nodes indicate bootstrap percentages from 1000 replicates. Bar, 0.02 substitutions per nucleotide position. 
has contributed much to our knowledge of intestinal bacteriology and anaerobic bacteriology in general).

Cells are Gram-negative, obligately anaerobic, non-sporeforming, non-motile, rod-shaped and 0.8-1.6 $\times 1.7-11 \mu \mathrm{m}$ in size. On EG agar plates, colonies are 1-2 $\mathrm{mm}$ in diameter, grey to off-white-grey, circular, entire, slightly convex and smooth. Saccharolytic. Growth is inhibited on a medium containing $20 \%$ bile. Aesculin is hydrolysed. Indole is not produced. The DNA G $+\mathrm{C}$ content is $52 \mathrm{~mol} \%$. The genus Barnesiella is a member of the family Porphyromonadaceae. The type species is Barnesiella viscericola.

\section{Description of Barnesiella viscericola sp. nov.}

Barnesiella viscericola [vis.ce.ri'co.la. L. neut. n. viscus, visceris intestine; L. suff. n. -cola (from L. n. incola) inhabitant; N.L. fem. n. viscericola inhabitant of the intestine].

Exhibits the following characteristics in addition to those given in the description of the genus. Urease is not produced. Catalase is not produced. Gelatin is digested. Acid is produced from D-cellobiose, glucose, maltose, Dmannose and sucrose, but not from L-arabinose, glycerol, lactose, D-mannitol, D-melezitose, D-raffinose, L-rhamnose, salicin, D-sorbitol, D-trehalose or D-xylose. Positive reactions are obtained using the Rapid ID 32A tests for $\alpha$ galactosidase, $\beta$-galactosidase, $\alpha$-glucosidase, $\beta$-glucosidase, $N$-acetyl- $\beta$-glucosaminidase, glutamic acid decarboxylase, $\alpha$-fucosidase, alkaline phosphatase, leucyl glycine arylamidase and alanine arylamidase. Raffinose is fermented. All of the other tests give negative results. The major end products are acetic acid and succinic acid; lower levels of other acids may be produced. Both non-hydroxylated and 3-hydroxylated long-chain fatty acids are present. The major cellular fatty acids are anteiso- $\mathrm{C}_{15: 0}$ and iso- $\mathrm{C}_{15: 0}$. The predominant respiratory quinones are MK-11 (65-66 \%) and MK-12 $(21-24 \%)$. MK-10 is present as a minor menaquinone $(10-11 \%)$. The DNA G + C content of the type strain is $52 \mathrm{~mol} \%$.

The type strain, $C 46^{\mathrm{T}}\left(=\mathrm{JCM} 13660^{\mathrm{T}}=\mathrm{DSM} 18177^{\mathrm{T}}\right)$, was isolated from chicken caecum. One additional strain, C47 (=JCM 13661), is included in this species.

\section{Acknowledgements}

We are grateful to Professor Dr H. Trüper, University of Bonn, Germany, for his suggestions regarding nomenclature. This work was supported, in part, by a Grant-in-Aid for Scientific Research (no. 16255001) from the Japan Society for the Promotion of Science.

\section{References}

Chen, S. \& Dong, X. (2005). Proteiniphilum acetatigenes gen. nov., sp. nov., from a UASB reactor treating brewery wastewater. Int $J$ Syst Evol Microbiol 55, 2257-2261.

Eckburg, P. B., Bik, E. M., Bernstein, C. N., Purdom, E., Dethlefsen, L., Sargent, M., Gill, S. R., Nelson, K. E. \& Relman, D. A. (2005).
Diversity of the human intestinal microbial flora. Science 308, 1635-1638.

Felsenstein, J. (1985). Confidence limits of phylogenies: an approach using the bootstrap. Evolution 39, 783-791.

Hofstad, T., Olsen, I., Eribe, E. R., Falsen, E., Collins, M. D. \& Lawson, P. A. (2000). Dysgonomonas gen. nov. to accommodate Dysgonomonas gadei sp. nov., an organism isolated from a human gall bladder, and Dysgonomonas capnocytophagoides (formerly CDC group DF-3). Int J Syst Evol Microbiol 50, 2189-2195.

Holdeman, L. V., Cato, E. P. \& Moore, W. E. C. (1977). Anaerobe Laboratory Manual, 4th edn. Blacksburg, VA: Virginia Polytechnic Institute and State University.

Kimura, M. (1980). A simple method for estimating evolutionary rates of base substitutions through comparative studies of nucleotide sequences. J Mol Evol 16, 111-120.

Komagata, K. \& Suzuki, K. (1987). Lipid and cell wall analysis in bacterial systematics. Methods Microbiol 19, 161-207.

Kuykendall, L. D., Roy, M. A., O’Neill, J. J. \& Devine, T. E. (1988). Fatty acids, antibiotic resistance, and deoxyribonucleic acid homology groups of Bradyrhizobium japonicum. Int J Syst Bacteriol 38, 358-361.

Lan, P. T. N., Hayashi, H., Sakamoto, M. \& Benno, Y. (2002). Phylogenetic analysis of cecal microbiota in chicken by the use of 16S rDNA clone libraries. Microbiol Immunol 46, 371-382.

Lan, P. T. N., Sakamoto, M., Sakata, S. \& Benno, Y. (2006). Bacteroides barnesiae sp. nov., Bacteroides salanitronis sp. nov. and Bacteroides gallinarum sp. nov., isolated from chicken caecum. Int J Syst Evol Microbiol 56, 2853-2859.

Lawson, P. A., Falsen, E., Inganäs, E., Weyant, R. S. \& Collins, M. D. (2002). Dysgonomonas mossi sp. nov., from human sources. Syst Appl Microbiol 25, 194-197.

Marmur, J. (1961). A procedure for the isolation of deoxyribonucleic acid from microorganisms. J Mol Biol 3, 208-218.

Miller, L. T. (1982). Single derivatization method for routine analysis of bacterial whole-cell fatty acid methyl esters, including hydroxy acids. J Clin Microbiol 16, 584-586.

Mitsuoka, T., Morishita, Y., Terada, A. \& Yamamoto, S. (1969). A simple method ("plate-in-bottle method") for the cultivation of fastidious anaerobes. Jpn J Microbiol 13, 383-385.

Saito, H. \& Miura, K. (1963). Preparation of transforming deoxyribonucleic acid by phenol treatment. Biochim Biophys Acta 72, 619-629.

Saitou, N. \& Nei, M. (1987). The neighbor-joining method: a new method for reconstructing phylogenetic trees. Mol Biol Evol 4, 406-425.

Sakamoto, M. \& Benno, Y. (2006). Reclassification of Bacteroides distasonis, Bacteroides goldsteinii and Bacteroides merdae as Parabacteroides distasonis gen. nov., comb. nov., Parabacteroides goldsteinii comb. nov. and Parabacteroides merdae comb. nov. Int J Syst Evol Microbiol 56, 1599-1605.

Sakamoto, M., Suzuki, M., Umeda, M., Ishikawa, I. \& Benno, Y. (2002). Reclassification of Bacteroides forsythus (Tanner et al. 1986) as Tannerella forsythensis corrig., gen. nov., comb. nov. Int J Syst Evol Microbiol 52, 841-849.

Sakamoto, M., Huang, Y., Umeda, M., Ishikawa, I. \& Benno, Y. (2005). Prevotella multiformis sp. nov., isolated from human subgingival plaque. Int J Syst Evol Microbiol 55, 815-819.

Shah, H. N. (1992). The genus Bacteroides and related taxa. In The Prokaryotes, 2nd edn, pp. 3593-3607. Edited by A. Balows, H. G. Trüper, M. Dworkin, W. Harder \& K. H. Schleifer. New York: Springer. 
Tamaoka, J. \& Komagata, K. (1984). Determination of DNA base composition by reversed-phase high-performance liquid chromatography. FEMS Microbiol Lett 25, 125-128.

Thompson, J. D., Higgins, D. G. \& Gibson, T. J. (1994). CLUSTAL W: improving the sensitivity of progressive multiple sequence alignment through sequence weighting, position-specific gap penalties and weight matrix choice. Nucleic Acids Res 22, 4673-4680.
Ueki, A., Akasaka, H., Suzuki, D. \& Ueki, K. (2006). Paludibacter propionicigenes gen. nov., sp. nov., a novel strictly anaerobic, Gramnegative, propionate-producing bacterium isolated from plant residue in irrigated rice-field soil in Japan. Int J Syst Evol Microbiol 56, 39-44.

Zhu, X. Y., Zhong, T., Pandya, Y. \& Joerger, R. D. (2002). 16S rRNAbased analysis of microbiota from the cecum of broiler chickens. Appl Environ Microbiol 68, 124-137. 